\title{
Penerapan Konsep Adaptive Reuse pada Desain Interior Café di Kawasan Kota Lama Semarang (Studi Kasus: Tekodeko Koffiehuis)
}

\author{
Noeratri Andanwerti ${ }^{1}$, Adi Ismanto ${ }^{2}$, Fivanda ${ }^{3}$ \\ ${ }^{1,2,3}$ Program Studi Desain Interior, Universitas Tarumanagara \\ Email: noeratria@fsrd.untar.ac.id
}

\begin{abstract}
Kawasan Kota Lama Semarang yang didalamnya terdapat bangunan bersejarah, saat ini dijadikan destinasi wisata unggulan yang menarik perhatian wisatawan domestik maupun mancanegara untuk berkunjung ke Kota Semarang. Untuk menjaga kelestarian dan revitalisasi melalui pemugaran bangunan dengan pendekatan adaptive reuse, mengganti fungsi baru bangunan lama menjadi museum, perkantoran, restoran, café dan lainnya.

Tujuan penelitian ini adalah untuk memahami masalah yang dihadapi pemilik bangunan lama, pengelola dan arsitek dalam penerapan konsep adaptive reuse, yaitu dengan memasukkan fungsi baru akan berdampak pada fisik bangunan bersejarah yang memiliki berbagai persyaratan-persyaratan yang wajib dipatuhi dan mengetahui bagaimana gaya desain interior dan furniture dalam penerapan fungsi baru dari bangunan bersejarah. Metode kualitatif dilakukan melalui kajian sejarah untuk membandingkan perubahan bentuk, estetika dan fungsi lama/asal dari objek penelitian dan melalui berbagai wawancara dengan pengelola bangunan dan praktisi arsitek konservasi yang menangani pekerjaan revitalisasi. Hasil penelitian ini menggambarkan adaptasi fungsi cafe pada bangunan lama ini terjadi perubahan pada struktur dan kulit bangunan dengan pendekatan visual yang selaras dengan karakter visual warisan budaya kolonial sehingga keberlanjutan bangunan terhadap lingkungan dapat terjaga. Pada bagian interiornya terjadi perubahan yang cukup signifikan untuk mengakomodasi fungsi ruang komersial.
\end{abstract}

Kata kunci:, desain interior, café, adaptive reuse, konservasi

\section{PENDAHULUAN}

Terdaftarnya Kota Lama Semarang menjadi salah satu tentative list cagar budaya di dunia yang diakui oleh UNESCO (The United Nations Educational, Scientific and Cultural Organization) merupakan bukti komitmen pemerintah daerah dalam melestarikan kawasan tersebut. Bentuk komitmen lainnya yang dilakukan oleh pemerintah daerah adalah menetapkan kawasan Kota Lama sebagai kawasan cagar budaya yang harus dilindungi kelestariannya di dalam Rencana Tata Ruang dan Wilayah (RTRW) Kota Semarang dan mengatur pengembangannya melalui penerbitan dokumen Rencana Tata Bangunan dan Lingkungan (RTBL) Kawasan Kota Lama.
Kota Lama Semarang mengalami berbagai tekanan yang mengancam keberadaannya, mulai dari tekanan pembangunan ekonomi hingga dampak globalisasi. Berbagai upaya telah dilakukan untuk menjaga kelestarian cagar budaya yang ada, seperti melakukan restorasi bangunan; adaptive reuse menjadi museum, perkantoran, restoran, dan lainnya; hingga melakukan kerja sama pemerintah dan swasta untuk menjaga dan mengembalikan vitalitas kawasan ini. (Sari, Harani, \& Werdiningsih, 2017)

Beberapa tahun terakhir telah muncul upaya-upaya untuk menimbulkan kepedulian dan pemahaman di masyarakat mengenai "berharganya" kawasan Kota Lama ini. Salah 
satunya melalui penyelenggaraan Festival Kota Lama, community activities, workshop, pameran, dan lainnya. Selain itu juga, adanya adaptive reuse menjadi museum, perkantoran, dan restoran merupakan usaha yang sangat baik agar kawasan ini kembali dimaknai oleh masyarakat. Salah satu bentuk adaptive reuse yang telah dilakukan di Kota Lama Semarang adalah penggunaan kembali bangunan kantor perusahaan Winkel Maatschappij menjadi art gallery.

Dalam penelitian ini akan dikaji bagaimana penerapan konsep adaptive reuse bangunan bersejarah lainnya di kawasan Kota Lama Semarang yang juga memiliki nilai komersial. Penerapan konsep ini akan diteliti melalui aspek bangunan dan interiornya. Diharapkan kajian ini dapat menjadi pertimbangan desain interior untuk mengimplementasikan konsep adaptive reuse bangunan bersejarah secara tepat dan bijaksana. Diharapkan dalam jangka panjang kajian ini nantinya dapat meningkatkan kualitas pengembangan Kota Lama pada khususnya.

\section{METODE}

Penelitian ini merupakan penelitian kualitatif dengan memilih objek bangunan bersejarah di kawasan kota Lama Semarang yang saat ini memiliki fungsi komersial dan berperan dalam kegiatan pariwisata daerah. Maka dipilih studi kasus objek: Tekodeko
Koffiehuis yang berada di Jalan Letjen Suprapto No. 44, Tanjung Mas, Kota Semarang. Pengambilan data lapangan dilakukan secara langsung maupun tidak langsung. Pengambilan data secara langsung dilakukan di lokasi. Sementara secara tidak langsung, data didapat melalui wawancara narasumber arsitek konservasi dan perwakilan komunitas pendukung pariwisata Kota Lama Semarang yang menggunakan fasilitas di objek penelitian.

Penelitian ini menggunakan studi kasus bangunan bersejarah yang memiliki fungsi komersial dan berperan dalam kegiatan pariwisata di Kota Lama Semarang. Data penelitian ini diperoleh dari studi literatur, hasil pengukuran dan observasi lapangan, wawancara dengan pengelola, arsitek konservasi, diskusi kelompok dengan pembahasan terhadap desain bangunan dan interior konsep adaptive reuse.

Analisis data dilakukan dengan metode triangulasi dengan membandingkan data dari beberapa sumber, kemudian mengelompokkan, menyeleksi, dan menyimpulkan. Penelitian ini juga menggunakan pendekatan sejarah dengan membandingkan data terkini dengan data sebelum revitalisasi/adaptasi fungsi baru. Penelitian ini juga menggunakan metode analisis visual dari foto dokumentasi. Hasil 
penelitian yang didapatkan nantinya berupa kriteria dan rekomendasi untuk desain bangunan bersejarah yang menerapkan konsep adaptive reuse untuk fungsi komersial.

Menurut Bullen (2007) meskipun ada banyak faktor kualifikasi, konsep adaptive reuse memiliki dukungan yang signifikan sebagai strategi positif untuk membuat lingkungan yang dibangun lebih berkelanjutan. Adaptive reuse meningkatkan kegunaan jangka panjang suatu bangunan dan merupakan pilihan yang lebih berkelanjutan daripada pembongkaran dan pembangunan kembali. Manfaat positif adaptive reuse yang juga mendukung prinsip keberlanjutan dan termasuk: mengurangi konsumsi sumber daya, penggunaan energi dan emisi; memperpanjang masa manfaat bangunan; lebih hemat biaya daripada pembongkaran dan pembangunan kembali; reklamasi energi yang terkandung dalam kerangka waktu yang lebih besar; menciptakan sumber daya masyarakat yang berharga dari properti yang tidak produktif; merevitalisasi lingkungan yang ada; mengurangi konsumsi lahan dan perluasan kota; meningkatkan daya tarik estetika lingkungan binaan; meningkatkan permintaan untuk mempertahankan bangunan yang ada; mempertahankan jalanan yang mempertahankan rasa tempat (sense of place); dan mempertahankan kenyamanan visual dan warisan budaya.

\section{HASIL DAN PEMBAHASAN}

\section{A. Gambaran Umum Kawasan Kota Lama}

\section{Semarang}

Kota Lama Semarang merupakan kawasan cikal bakal perkembangan Kota Semarang yang dibangun pada tahun 1742 dan memiliki luas sekitar 31,4 ha. Kota Lama Semarang pada awal masa berdirinya merupakan kawasan pusat pemerintahan, perkantoran dan perdagangan yang paling ramai di Jawa Tengah. Bangunan-bangunan di Kawasan Kota Lama umumnya dimanfaatkan sebagai gudang-gudang milik pengusaha yang menjadi pemilik sah atas tanah di Kota Lama. Pemanfaatan bangunan menjadi pergudangan ini memberikan kesan kumuh dan tidak aman untuk kawasan Kota Lama. Hal ini dikarenakan aktivitas bongkar muat barang pada gudang yang tidak rutin dan bersifat periodik membuat pemanfaatan bangunan sangat minim aktivitas. Hal ini menjadikan kota Lama terkesan sangat sepi pada malam hari. Hanya beberapa bangunan yang digunakan sebagai aktivitas publik, seperti tempat makan dan tempat peribadatan.

Kualitas lingkungan yang buruk di Kota Lama juga menjadi salah satu permasalahan rumit bagi pemerintah Kota Semarang, serta keamanan kawasan Kota Lama sebagai salah 
satu tujuan wisatawan juga merupakan permasalahan lain yang harus diselesaikan. Kualitas lingkungan ini menyangkut dengan permasalahan banjir yang tidak kunjung usai di Kota Lama. Pada tahun 2013, pesisir Kota Semarang yang mengalami banjir hebat berdampak kepada Kota Lama.

Menurut Nik Suryatin, berdasarkan inventarisasi Pemerintah Daerah Tingkat II Semarang pada tahun 2006 terdapat sekitar 261 benda cagar budaya yang dilindungi di Wilayah Kotamadya Daerah Tingkat II Semarang. Terhadap bangunan-bangunan kuno / bersejarah tersebut berdasarkan Surat Keputusan Walikotamadya Kepala Daerah Tingkat II Semarang No. 646/50/Tahun 1992 tersebut harus dilakukan konservasi, yaitu segenap proses pengelolaan suatu tempat, khususnya menyangkut bangunan kuno / bersejarah, agar makna kultural yang dikandungnya terpelihara dengan baik, yang mencakup :

(1) Preservasi, yaitu pelestarian suatu bangunan kuno / bersejarah seperti keadaan aslinya tanpa adanya perubahan, termasuk upaya mencegah atau menangkal penghancuran.

(2) Restorasi atau rehabilitasi, yaitu pengembalian suatu bangunan kuno / bersejarah ke keadaan semula, dengan menghilangkan tambahan dan memasang komponen asli semula tanpa menggunakan bahan baru.

(3) Rekonstruksi, yaitu pengembalian suatu bangunan kuno / bersejarah semirip mungkin dengan keadaan semula, baik menggunakan bahan lama maupun bahan baru.

(4) Adaptasi atau revitalisasi (adaptive reuse) yaitu mengubah kegunaan fungsi yang lebih sesuai, tanpa melakukan perubahan menyeluruh atau hanya mengakibatkan dampak sekecil mungkin

\section{B. Identifikasi Objek Penelitian}

Lokasi objek penelitian Tekodeko Koffiehuis di Jalan Letjen Suprapto no. 44, Tanjung Mas Semarang Utara, Kota Semarang. Berdasarkan hasil wawancara dengan Arsitek dan Ahli Konservasi Ir. A. Kriswandono, M.Si. Tekodeko Koffiehuis merupakan bangunan yang termasuk bangunan cagar budaya.

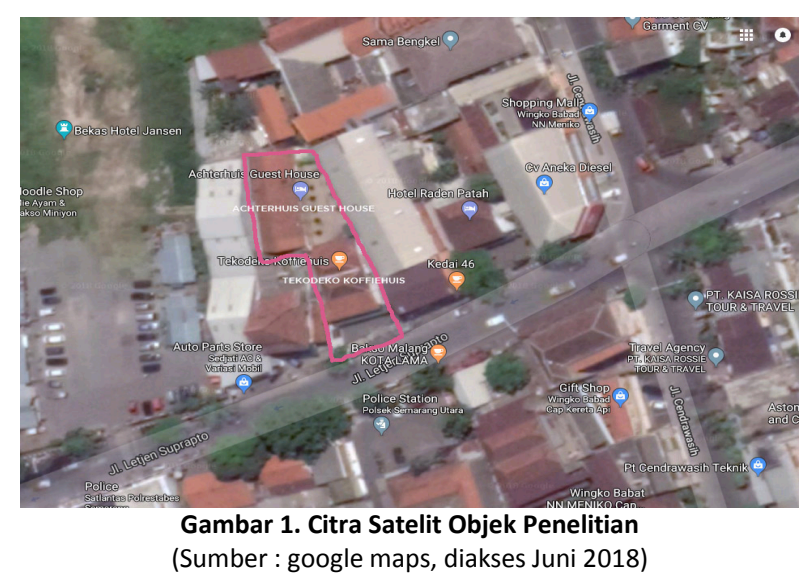

Status kepemilikannya bangunan Tekodeko Koffiehuis dipegang oleh perorangan yaitu Ibu 
Sintiana Rahayu seorang pengusaha asal kota Semarang. Namun seiring perkembangan usaha café ini dimiliki sekelompok orang muda yang sekaligus mengelola Tekodeko Koffiehuis, mereka adalah Ronny Jonathan, Jessie Setiawati, dan Kriski Laras. Pemilik bangunan dan pengelola bekerjasama mengelola bisnis dengan sistem pembagian saham. Tekodeko Koffiehuis berdiri sejak tahun 2015. Nama 'Tekodeko' diambil dari kata 'Teko' yang merupakan tempat air minum, dan 'Deko' diambil dari kata dekorasi yang berarti tata ruang dari sebuah bangunan. Pada kenyataannya Tekodeko Koffiehuis telah menjadi destinasi wisatawan yang berkunjung ke Kota Lama, hal ini diperkuat dengan data di situs pencarian daring Google.

Bangunan yang kini ditempati Tekodeko Koffiehuis merupakan bangunan bersejarah yang dibangun sekitar tahun 1880-an. Sejumlah pelanggan berusia paruh baya yang sering berkunjung ke kedai kopi ini mengatakan, bangunan tersebut dulu merupakan milik seorang bangsawan dan berfungsi sebagai tempat tinggal. Pada awal 1930, bangunan ini berubah fungsinya menjadi pabrik kusen. Fungsi itu bertahan hingga bangunan ini berubah fungsi menjadi kedai kopi: Tekodeko Koffiehuis.

\section{B. Identifikasi Perubahan Arsitektural Objek Penelitian}

Bangunan Tekodeko Koffiehuis berlantai 2 yang memiliki konstruksi atap limas. Secara bentuk, bangunan berciri khas bangunan kolonial Belanda dengan struktur empat kolom ekspos di bagian fasad bangunan. Pada bagian sisi kanan terdapat pintu sebagai akses menuju penginapan Achterhuis Guest House yang berlokasi di bagian belakang bangunan ini.

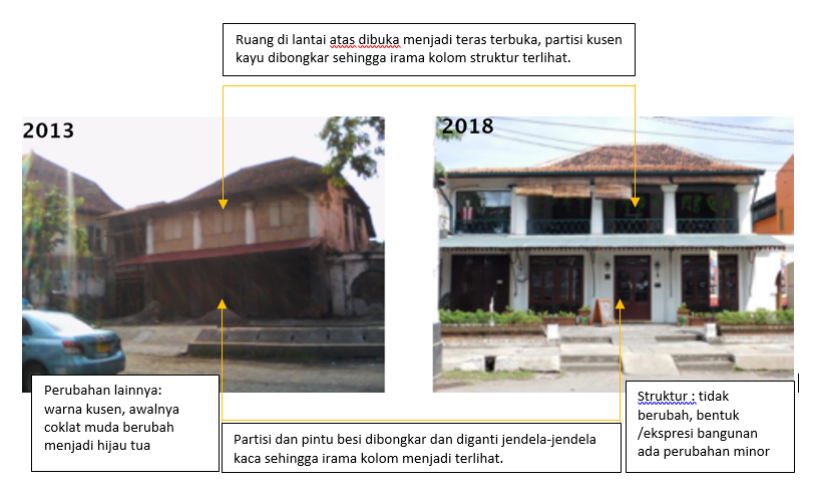

Gambar 2. Analisis Perubahan Fasad Bangunan Sebelum (2013) dan Sesudah Pemugaran (2018) (Sumber: Peneliti, 2018)

\section{Identifikasi Fungsi dan Tata Ruang Objek Penelitian}

Bangunan Tekodeko Koffiehuis terdiri dari 2 (dua) lantai dan memiliki ruang indoor dan ruang outdoor. Bagian lantai dasar diperuntukkan sebagai ruang duduk untuk pelanggan secara umum, dan bagian lain terdapat bar, dapur dan ruang pengelola. Sedangkan di lantai atas digunakan untuk pelanggan khusus: komunitas sosial budaya berupa ruang duduk dibagian dalam dan teras, ruang meeting, dan ruang yang disewakan, dan saat ini ruang tersebut disewakan untuk butik. 
Berdasarkan hasil wawancara dengan Arsitek dan Ahli Konservasi Ir. A. Kriswandono, M. Si. yang dilakukan pada bulan April 2018, bangunan Tekodeko Koffiehuis ini awalnya merupakan bangunan rumah tinggal yang telah beberapa kali berganti kepemilikan. Pemilik terakhir yaitu Ibu Sintiana Rahayu, menggunakan bangunan ini sebagai took dan pabrik kusen yang dibagian belakangnya terdapat fungsi gudang dan bengkel kayu. Tekodeko Koffiehouse dan bangunan penginapan di belakangnya memiliki luas bangunan total $3100 \mathrm{~m}^{2}$ di tanah seluas 10.770 $\mathrm{m}^{2}$
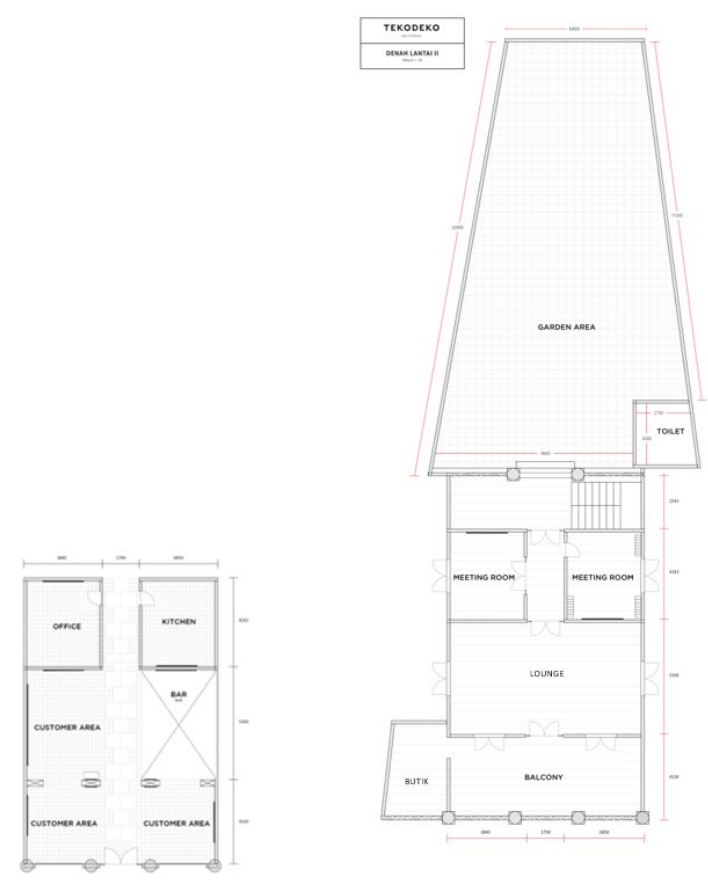

Gambar 3. Denah Lantai Dasar dan Lantai Atas (Sumber : Tekodeko Koffiehuis, 2018)

Berdasarkan Daftar Bangunan Sejarah di Kawasan Kota Lama Semarang versi Lampiran Perda Kota Semarang No. 8 Tahun 2003 tentang RTBL Kota Lama Semarang, bangunan
Tekodeko Koffiehuis merupakan bangunan bersejarah yang memiliki kriteria fungsi gudang. Pemilik dalam upaya melakukan revitalisasi untuk mempertahankan bangunan sekaligus menghasilkan pendapatan dengan mengubah fungsi bangunan rumah tinggal ini menjadi bangunan mix-use yaitu sebagai tempat usaha: café /kedai kopi, penginapan/budget hotel dan ruang pertemuan untuk komunitas sosial budaya di kota Semarang. Revitalisasi dilaksanakan pada tahun 2014-2015 diawasi langsung oleh Ir. A. Kriswandono, M. Si. sebagai arsitek konservasi sekaligus anggota Badan Pengelola Kawasan Kota Lama (BPK2L) pada saat itu.

Dalam penerapan konsep adaptive reuse, arsitek mempertahankan bentuk struktur ruang dalam sesuai bentuk aslinya, dengan mempertahankan kolom, dinding, lantai yang ada, dengan menambahkan penguatanpenguatan agar bangunan lebih kokoh. Pada dinding bagian depan, awalnya bangunan ini yang berfungsi sebagai gudang menggunakan pintu lipat besi yang kemudian diganti dengan jendela-jendela kaca dengan dimensi yang cukup tinggi untuk mendukung fungsi baru sebagai kedai kopi yang membutuhkan estetika, pencahayaan alami dan suasana yang lebih baik di ruang dalam dan tampak luar bangunan juga lebih menarik. Jendela kaca berkusen kayu, ini diselaraskan bentuk dan 
komposisinya sesuai dengan karakter bangunan warisan jaman kolonial.

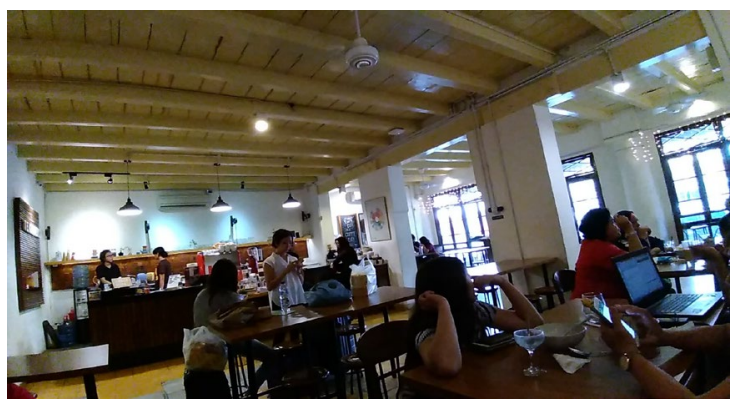

Gambar 5. Interior Area Customer Lantai Dasar (Sumber : Peneliti, 2018)

Bahan lantai asli adalah marmer dan ada beberapa bagian yang hilang dan rusak. Penggantian sebagian bahan lantai marmer dilakukan oleh arsitek, karena bahan lantai marmer sejenis tidak ditemukan di pasar bahan lantai local, maka sebagian lantai ini menggunakan tegel teraso. Tegel teraso dipilih yang memiliki karakter material yang memiliki khas produksi jaman dahulu, dan dipilih tegel berwarna kuning.

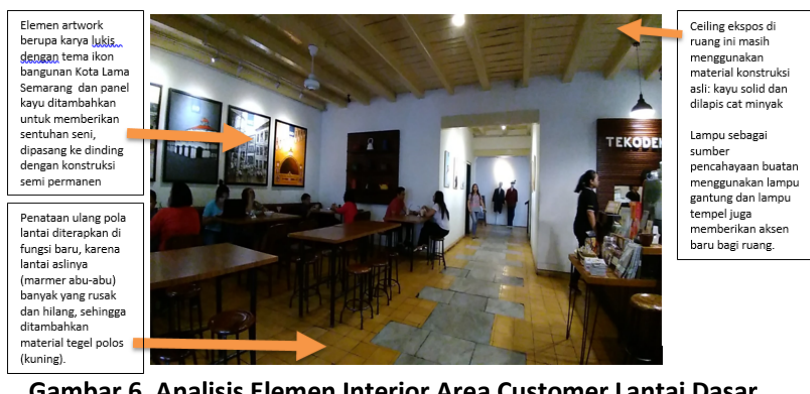

Gambar 6. Analisis Elemen Interior Area Customer Lantai Dasar (Sumber : Peneliti, 2018)

Pada area bar, terdapat perubahan penataan lantai, yaitu penaikan lantai setinggi $20 \mathrm{~cm}$. Hal ini dilakukan untuk memberikan ruang untuk penempatan jalur pipa air bersih dan air kotor, agar tidak banyak membongkar lantai dan bagian dasar bangunan. Penaikan lantai bar ini juga memberikan ketinggian yang cukup untuk fungsi pengawasan bagi pengelola terhadap keseluruhan ruang. Pada area bar terdapat dinding di atas meja persiapan, yang dilapis batu bata untuk melapisi dinding agar tidak lekas rusak karena air, juga memberikan aksen dekoratif terhadap ruang secara keseluruhan.

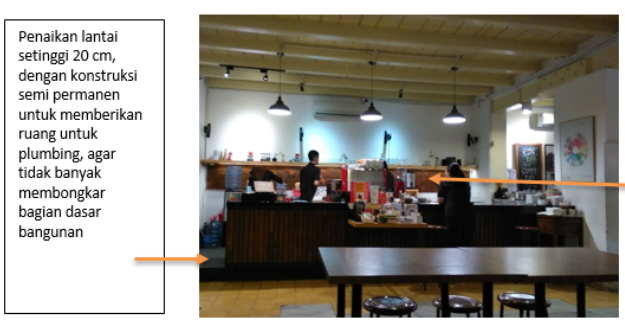
\begin{tabular}{|l|}
\hline Dinding diberi \\
lapisan tambahan \\
berupa batu bata \\
setinggi $40 \mathrm{~cm}$ \\
untuk melapisi \\
dinding area basah \\
di atas meja \\
persiapan di area \\
Bar, juga \\
memberikan aksen \\
dekoratif terhadap \\
ruang secara \\
keselutuhan. \\
\hline
\end{tabular}

Gambar 7. Analisis Elemen Interior Area Bar (Sumber : Peneliti, 2018)

Penataan cahaya di ruang dalam café terdapat pencahayaan buatan dengan menerapkan lampu sorot, lampu gantung dan indirect lighting yang secara umum menggunakan lampu berwarna putih hangat (warm white). Pencahayaan alami secara terbatas hanya dapat masuk dari jendelajendela kaca pada bagian depan café, sehingga dibutuhkan tambahan pencahayaan buatan sepanjang hari.

Café ini berlokasi dekat dengan wilayah pesisir pantai, yang memiliki tingkat suhu udara sekitar $24-33^{\circ} \mathrm{C}$ dan kelembaban diatas 70\% perlu dilengkapi fasilitas pengkondisian udara(AC) sepanjang hari. Bangunan yang 
digunakan ulang ini tidak memiliki ventilasi udara.

\section{Analisis Penerapan Adaptive Reuse pada Objek Penelitian}

Untuk hasil identifikasi penerapan adaptive reuse pada desain interior cafe ini, dapat dijelaskan sebagai berikut:

Tabel 1. Analisis Penerapan Adaptive Reuse Pada Objek Penelitian

\begin{tabular}{|c|c|c|c|}
\hline No & Komponen & Fungsi Lama & Fungsi Baru \\
\hline 1 & $\begin{array}{l}\text { Organisasi } \\
\text { Ruang }\end{array}$ & $\begin{array}{l}\text { Bagian depan: } \\
\text { Rumah Tinggal } \\
\text { Bagian belakang: } \\
\text { Bengkel+Gudang }\end{array}$ & $\begin{array}{l}\text { Bagian depan: Mixed use (Kedai } \\
\text { kopi, ruang meeting, wadah } \\
\text { komunitas, office) } \\
\text { Bagian belakang: } \\
\text { Penginapan dan office } \\
\text { Fungsi baru menyesuaikan } \\
\text { perkembangan kebutuhan } \\
\text { sosial masyarakat }\end{array}$ \\
\hline 2 & $\begin{array}{l}\text { Aspek } \\
\text { Bangunan }\end{array}$ & $\begin{array}{l}\text { Bangunan Utama : } \\
2 \text { lantai - } \\
\text { permanen } \\
\text { Bangunan } \\
\text { Penunjang: } \\
1 \text { lantai- semi } \\
\text { permanen }\end{array}$ & $\begin{array}{l}\text { Struktur Bangunan Utama tidak } \\
\text { berubah/ dipertahankan dan } \\
\text { perubahan disesuaikan dengan } \\
\text { bentuk aslinya } \\
\text { Bangunan Penunjang: } \\
\text { dibongkar total, dan dibangun } \\
\text { yang baru }\end{array}$ \\
\hline & & $\begin{array}{l}\text { Bangunan Utama: } \\
\text { Bangunan } \\
\text { permanen } 2 \text { lantai } \\
\text { dalam kondisi } \\
\text { rusak } \\
\text { Bangunan } \\
\text { Penunjang: } \\
\text { sebidang tanah } \\
\text { yang terdapat } \\
\text { bangunan semi } \\
\text { permanen dalam } \\
\text { keadaan rusak }\end{array}$ & $\begin{array}{l}\text { Bangunan Utama: } \\
\text { Bangunan permanen } 2 \text { lantai } \\
\text { dengan penambahan bagian } \\
\text { teras belakang di lantai } 2 \\
\text { dengan konstruksi beton. } \\
\text { Bangunan Penunjang: } \\
\text { Bangunan Semi permanen } \\
\text { untuk penginapan yang terdiri } \\
\text { dari } 2 \text { lantai, kamar-kamar ini } \\
\text { berderet dan dihubungkan } \\
\text { dengan koridor/teras terbuka }\end{array}$ \\
\hline 3 & $\begin{array}{l}\text { Fasad } \\
\text { Bangunan }\end{array}$ & $\begin{array}{l}\text { Lantai } 1 \text { bangunan } \\
\text { utama } \\
\text { menggunakan } \\
\text { pintu besi lipat } \\
\text { dan teralis ciri } \\
\text { yang menjadi ciri } \\
\text { khas bangunan } \\
\text { fungsi toko } \\
\text { Lantai 2, tertutup } \\
\text { dengan dinding } \\
\text { dan jendela kayu } \\
\text { solid }\end{array}$ & $\begin{array}{l}\text { Lantai } 1 \text { bangunan utama } \\
\text { dibuka dengan menggunakan } \\
\text { bukaan berupa jendela dan } \\
\text { pintu kaca dengan langgam } \\
\text { yang disesuaikan dengan } \\
\text { langgam bangunan kolonial }\end{array}$ \\
\hline 4 & $\begin{array}{l}\text { Aspek } \\
\text { Interior } \\
\text { (Organisasi } \\
\text { Ruang) }\end{array}$ & $\begin{array}{l}\text { Bagian depan: } \\
\text { Ruang-ruang di } \\
\text { bangunan } 2 \text { lantai } \\
\text { ini digunakan } \\
\text { sebagai gudang } \\
\text { sehingga kondisi } \\
\text { lantai, dinding dan } \\
\text { ceiling banyak } \\
\text { yang rusak. }\end{array}$ & $\begin{array}{l}\text { Bagian Depan: } \\
\text { Ruang-ruang di lantai dasar } \\
\text { digunakan secara umum untuk } \\
\text { area customer, bar, kitchen, } \\
\text { kantor pengelola café. } \\
\text { Di lantai atas digunakan untuk } \\
\text { area customer khusus dari } \\
\text { berbagai komunitas, terdapat } \\
\text { ruang meeting, area balkon da } \\
\text { area teras terbuka di bagian } \\
\text { belakang, serta toilet }\end{array}$ \\
\hline
\end{tabular}

\begin{tabular}{|l|l|l|}
\hline & Bagian Belakang: & Bagian Belakang: \\
& Bangunan semi & Bangunan memiliki 20 kamar \\
& permanen rusak & penginapan di lantai dasar dan \\
& tidak terawat & lantai atas, yang dilengkapi \\
& karena faktor & dengan kamar mandi dan \\
& waktu dan cuaca. & pendingin ruangan (AC) \\
\hline
\end{tabular}

\section{E. Rekomendasi Penerapan Adaptive}

\section{Reuse Di Bangunan Bersejarah}

Berdasarkan hasil analisis maka dapat diambil beberapa pokok rekomendasi untuk penerapan adaptive reuse di bangunan bersejarah:

1. Pihak pemilik bangunan bersejarah untuk menerapkan adaptive reuse penting melakukan konsultasi dengan arsitek/desainer ahli konservasi dan pihak terkait dalam hubungannya menjaga keberlanjutan bangunan bersejarah dan lingkungannya.

2. Perlu dokumentasi yang lengkap tentang objek di masa lalu dan eksisting sebagai acuan dalam melakukan perancangan ulang dengan pendekatan adaptive reuse

3. Perlu menganalisis fungsi lama bangunan dan fungsi baru yang akan diterapkan dan sejauhmana perubahan bentuk diperlukan sebagai konsekuensi.

4. Untuk kepentingan konservasi bangunan bersejarah perlu mempertahankan konsistensi gaya desain bangunan dan gaya desain interior 
Tabel 2. Rekomendasi Penerapan Adaptive Reuse Di Bangunan

\begin{tabular}{|c|c|c|}
\hline \multicolumn{3}{|c|}{ Bersejarah di Kota Lama Semarang } \\
\hline ASPEK & $\begin{array}{l}\text { BANGUNAN } \\
\text { LAMA }\end{array}$ & REKOMENDASI PENERAPAN \\
\hline FUNGSI & $\begin{array}{l}\text { Residential, } \\
\text { Toko dan } \\
\text { Pergudangan }\end{array}$ & $\begin{array}{l}\text { Café, Office, Community Center dan } \\
\text { Guesthouse }\end{array}$ \\
\hline STRUKTUR & $\begin{array}{l}\text { Bangunan } \\
\text { Utama: } \\
\text { Permanen } \\
\text { Bangunan } \\
\text { Tambahan: } \\
\text { Semi } \\
\text { permanen }\end{array}$ & $\begin{array}{l}\text { Bangunan Utama direnovasi dengan } \\
\text { mempertahankan nilai-nilai } \\
\text { keaslian/disesuaikan dengan } \\
\text { ekspresi bentuk aslinya } \\
\text { Dapat dibongkar total dan dibangun } \\
\text { yang baru }\end{array}$ \\
\hline FASAD & $\begin{array}{l}\text { Kondisi } \\
\text { masih } \\
\text { asli/sudah } \\
\text { ada } \\
\text { perubahan }\end{array}$ & $\begin{array}{l}\text { Renovasi menyesuaikan karakter } \\
\text { bangunan asli: bukaan seperti } \\
\text { jendela dan pintu dapat berkarakter } \\
\text { semi transparan agar ruang dalam } \\
\text { mendapatkan view (interaksi } \\
\text { dengan outdoor) }\end{array}$ \\
\hline INTERIOR & $\begin{array}{l}\text { Ceiling } \\
\text { Dinding } \\
\text { Lantai } \\
\text { Elemen } \\
\text { dekoratif }\end{array}$ & $\begin{array}{l}\text { Dinding dan ceiling arsitektur } \\
\text { dipertahankan/diperkuat dan } \\
\text { penerapan finishing sepereti cat } \\
\text { tembok/kayu yang sesuai dengan } \\
\text { karakter bangunan aslinya. } \\
\text { Lantai mempertahankan material } \\
\text { asli yang kondisinya baik. } \\
\text { Apabila kondisi material lantai } \\
\text { banyak yang rusak/hilang, maka } \\
\text { penataan ulang pola lantai dengan } \\
\text { menggunakan mix material asli dan } \\
\text { material tambahan yang } \\
\text { karakternya mendukung. } \\
\text { Elemen dekoratif dapat } \\
\text { menampilkan karakter dan fungsi } \\
\text { baru, serta konstruksinya bersifat } \\
\text { semi permanen. }\end{array}$ \\
\hline
\end{tabular}

\section{SIMPULAN}

Adaptive reuse atau revitalisasi, yaitu mengubah kegunaan fungsi yang lebih sesuai dengan perubahan kebutuhan masyarakat, tanpa melakukan perubahan menyeluruh atau hanya mengakibatkan dampak sekecil mungkin. Hal ini yang diterapkan pada bangunan cagar budaya di Jalan Letjen Suprapto no. 44 Semarang dengan mengubah fungsi rumah tinggal, gudang, bengkel menjadi bangunan mixed use: kedai kopi, penginapan dan wadah berkumpulnya komunitas- komunitas social budaya yang aktif di Kawasan Kota Lama Semarang.

Pemilik yang melibatkan arsitek konservasi dalam penerapan konsep adaptive reuse pada bangunan berupaya memenuhi peraturan pelestarian tentang keaslian bahan, bentuk, tata letak, dan/atau teknik pengerjaan untuk memperpanjang usia bangunan kuno, serta mempertahankan karakter visual bangunan lama selaras dengan arah revitalisasi Kawasan Kota Lama Semarang.

Penelitian menemukan perubahan-perubahan bangunan dan ruang untuk memenuhi kebutuhan baru. Perubahan ini dilakukan secara adaptif diterapkan agar tidak mengurangi esensi keaslian bangunan bersejarah. Gaya interior yang diterapkan dalam café ini mempertahankan gaya arsitektur aslinya dengan mempertahankan bentuk, bahan, namun dengan tambahan perubahan dan penggunaan warna-warna namun penggunaan cat pelapis dinding dan kusen-pintu kayu sesuai dengan arahan Dinas Cagar Budaya.

\section{UCAPAN TERIMA KASIH}

Tim Peneliti mengucapkan terimakasih kepada pihak-pihak terkait yang membantu dalam pelaksanaan penelitian ini, diantaranya Direktorat Penelitian dan Pengabdian Masyarakat Universitas Tarumanagara, 
Arsitek Konservasi Ir. A. Kriswandono, M. Si., Pengelola Tekodeko Koffiehuis dan Achterhuis Guest House.

\section{DAFTAR PUSTAKA}

Bullen, P.A. Adaptive reuse and sustainability of commercial buildings. Facilities 2007, 25, 20-31

Snyder, J. (1984). Architectural Research . New York: Van Nostrand Reinhold Company .

Tonapa, Y. N., Rondonuwu, D. M., \& Tungka, A. E. (2015). Kajian Konservasi Bangunan Kuno dan Kawasan Bersejarah Di Pusat Kota Lama Manado. Spasial, Vol. 2(No. 3).

Purwanto, L. (1996). Adaptasi Arsitektur Kolonial Belanda Iklim Terhadap Tropis Lembab Semarang. Thesis S2, Univeritas Diponegoro, Jurusan Arsitektur, Semarang.

Sofiana, R., Purwatiasning, A. W., \& Anisa. (2014). Strategi Penerapan Konsep Adaptive Reuse Pada Bangunan Tua Studi Kasus Gedung PT P.P.I. (Ex. Kantor Tjipta Niaga) Di Kawasan Kota Tua Jakarta. Seminar Nasional Sains dan Teknologi. Jakarta: Universitas Muhammadiyah Jakarta.

Austin, R. L., Woodcock, D. G., Stewart, W. C., \& Forrester, R. A. (1988). Adaptive Reuse: Issues and Case Studies in Building Preservation. Van Nostrand Reinhold.

Sari, S. R., Harani, A. R., \& Werdiningsih, H. (2017, Januari-Juni). Pelestarian Dan Pengembangan Kawasan Kota Lama Sebagai Landasan Budaya Kota Semarang. Modul, 17(1), 49-55.

Yanuarti, R. (2007). Perlindungan Hukum Terhadap Karya Arsitektur Cagar Budaya Ditinjau Dari Undang-Undang Nomor 19 Tahun 2002 Tentang Hak Cipta (Studi Kasus Perlindungan Arsitektur Cagar
Budaya di Kota Semarang). UNDIP, Arsitektur. Semarang: UNDIP. 